\title{
MicroRNAs, macrocontrol: Regulation of miRNA processing
}

\section{IZABELLA SLEZAK-PROCHAZKA, SELVI DURMUS, BART-JAN KROESEN, and ANKE VAN DEN BERG}

Department of Pathology and Medical Biology, University Medical Center Groningen, University of Groningen, 9700 RB, Groningen, The Netherlands

\begin{abstract}
MicroRNAs (miRNAs) are a set of small, non-protein-coding RNAs that regulate gene expression at the post-transcriptional level. Maturation of miRNAs comprises several regulated steps resulting in $\sim 22$-nucleotide single-stranded mature miRNAs. Regulation of miRNA expression can occur both at the transcriptional level and at the post-transcriptional level during miRNA processing. Recent studies have elucidated specific aspects of the well-regulated nature of miRNA processing involving various regulatory proteins, editing of miRNA transcripts, and cellular location. In addition, single nucleotide polymorphisms in miRNA genes can also affect the processing efficiency of primary miRNA transcripts. In this review we present an overview of the currently known regulatory pathways of miRNA processing and provide a basis to understand how aberrant miRNA processing may arise and may be involved in pathophysiological conditions such as cancer.
\end{abstract}

Keywords: microRNA; miRNA; biogenesis; processing; regulation

\section{INTRODUCTION}

MicroRNAs (miRNAs) are small $(\sim 22$-nucleotide $[\mathrm{nt}])$ noncoding RNA molecules that are single-stranded in the functional form (Bartel 2004). Unlike their small size, they play an important role in the regulation of gene expression at the post-transcriptional level. After their discovery in Caenorhabditis elegans (Lee et al. 1993; Wightman et al. 1993), there have been a large number of studies identifying miRNAs in animals, plants, and viruses. Their importance was confirmed in several cellular processes like development, cell fate determination, proliferation, and apoptosis. Moreover, altered miRNA expression profiles have been demonstrated in a large number of pathological conditions, such as cancer, suggesting that miRNAs are involved in disordered cellular function, such as malignant transformation.

miRNAs are located within introns and exons of proteincoding genes or in intergenic regions (Kim and Nam 2006). They are transcribed as long primary miRNA (pri-miRNA) transcripts containing one or more hairpin structures. Each hairpin structure consists of a double-stranded stem and

Reprint requests to: Anke van den Berg, Department Pathology and Medical Biology, University Medical Center Groningen, University of Groningen, 9700 RB, Groningen, The Netherlands; e-mail: a.van.den. berg@path.umcg.nl; fax: 31-50-3619107.

Article published online ahead of print. Article and publication date are at http://www.rnajournal.org/cgi/doi/10.1261/rna.1804410. a terminal loop. In the nucleus, the primary miRNA is cleaved by the Microprocessor complex, which consists of Drosha and DGCR8 (Lee et al. 2003; Denli et al. 2004; Gregory et al. 2004; Han et al. 2004; Landthaler et al. 2004). This cleavage step results in an $\sim 65$-nt precursor miRNA (pre-miRNA), which is exported from the nucleus to the cytoplasm in association with Exportin-5 and RanGTP (Yi et al. 2003; Bohnsack et al. 2004; Lund et al. 2004) and cleaved by Dicer to an $\sim 22$-nt miRNA duplex (Grishok et al. 2001; Hutvagner et al. 2001). One of the two strands is assembled into the RNA-induced silencing complex (RISC) together with one of the Argonaute (Ago) proteins. RISC can bind to the $3^{\prime}$-untranslated region (UTR) of the target mRNA based on a partial miRNA-mRNA complementarity. This binding causes a translational inhibition and/or degradation of the target mRNA (Eulalio et al. 2008; Filipowicz et al. 2008). However, not all miRNAs are processed by this so-called canonical biogenesis pathway. Alternatively, miRNAs can be generated from short intronic hairpins called mirtrons that are spliced and debranched to mimic premiRNA (Okamura et al. 2007; Ruby et al. 2007). Mirtrons bypass cleavage by Drosha, but nuclear export and further processing are common with the canonical miRNA processing pathway (Okamura et al. 2007; Ruby et al. 2007).

Biogenesis of miRNAs is tightly regulated resulting in characteristic miRNA expression patterns for different organisms, tissues, cell types, and developmental stages. It 
is known that transcription of miRNA genes can be regulated by epigenetic factors (Scott et al. 2006; Lehmann et al. 2007; Lujambio et al. 2007) or transcription factors (Xi et al. 2006; He et al. 2007; Woods et al. 2007). The inconsistencies between primary, precursor, and mature miRNA expression levels clearly indicate that the level of mature miRNAs can also be regulated at the level of miRNA processing. This review focuses on the mechanisms and factors that regulate miRNA processing, for example, regulatory proteins, cellular localization, and genetic variation.

\section{MECHANISMS FOR REGULATING MICRORNA PROCESSING}

Processing of miRNAs can be regulated at multiple steps and leads to either elevated or decreased miRNA levels. Altered miRNA levels may be caused by regulatory proteins that influence miRNA processing, acquired variations in the miRNA transcript, and by changes in the nuclear export efficiency. In addition to these regulatory mechanisms, single nucleotide polymorphisms (SNPs) can also have a pronounced effect on the efficiency of the miRNA processing machinery.

\section{Regulatory proteins}

Recently, a number of proteins that regulate miRNA processing have been described as key elements in defining the unique expression patterns of miRNAs in different cell types, tissues, or in pathological conditions. These proteins can be subdivided into three groups, i.e., Drosha binding/ associated proteins, Dicer binding proteins, and proteins that bind to the terminal loop of the pri- and/or premiRNAs.

\section{Drosha binding/associated proteins}

The Microprocessor complex consisting of Drosha and DGCR8 is sufficient to process pri-miRNA to pre-miRNA (Fig. 1A). However, Drosha was shown to be a component of a larger complex containing DEAD-box RNA helicases p68 (DDX5), p72 (DDX17), nuclear factor (NF) 90, and NF45 (Gregory et al. 2004). The p68/p72 and NF90/NF45 complexes have been shown to alter the miRNA processing efficiency for specific miRNAs (Fukuda et al. 2007; Davis et al. 2008; Sakamoto et al. 2009; Suzuki et al. 2009; Yamagata et al. 2009). Specifically, it has been shown that endogenous p68/p72 facilitate Drosha processing of a subset of pri-miRNAs based on reduced mature miRNA levels in both p72- and p68-helicase-deficient mouse embryos (Fukuda et al. 2007). Several studies showed that interaction of p68/p72 with other proteins also alters processing of specific primary miRNAs. Interaction of $\mathrm{p} 68$ with SMAD facilitates the processing of pri-miR-21 (Fig. 1B; Davis et al. 2008). The interaction of $\mathrm{p} 68$ with SMAD was induced by transforming growth factor $\beta$ (TGF- $\beta$ ) and bone morphogenetic proteins (BMPs). Similarly, wild-type p53 has been shown to associate with $\mathrm{p} 68$ and enhance processing of several primary miRNAs by Drosha, including pri-miRNA of miR-16-1, miR-143, and miR-145, in response to DNA damage (Fig. 1C; Suzuki et al. 2009). Moreover, wild-type p53 positively regulates Drosha-mediated processing by promoting recruitment of Drosha complex to the target pri-miRNAs, whereas mutant p53 hinders assembly of Drosha complex (Suzuki et al. 2009). Drosha-mediated processing can be inhibited by p68/p72-dependent mechanisms upon stimulation of estrogen receptor alpha (ER $\alpha)$ (Fig. 1D; Yamagata et al. 2009). This mechanism caused obstructed processing of a set of pri-miRNAs including miR-16, miR-125a, miR-143, miR-145, and miR-195 (Yamagata et al. 2009). Together these studies show that the p68/p72 complex is an important mediator of miRNA processing regulation and can direct Drosha toward either reduced or enhanced processing of specific miRNAs. The result of the interaction between Drosha, p68, and target pri-miRNA depends on proteins interacting with p68 like SMAD, p53, or ER $\alpha$. This indicates that the p68/p72dependent mechanism is sensitive to cellular context.

Two other members of the large Drosha-containing complex identified by Gregory et al. (2004), i.e., NF90 and NF45, were also shown to be involved in the regulation of miRNA processing (Fig. 1E). However, the interaction between Drosha and NF90/NF45 has not been confirmed for the endogenous Drosha-DGCR8 complex (Sakamoto et al. 2009). Nevertheless, overexpression of NF90/NF45 in 293T cells caused accumulation of pri-let-7a-1, pri-miR-21,

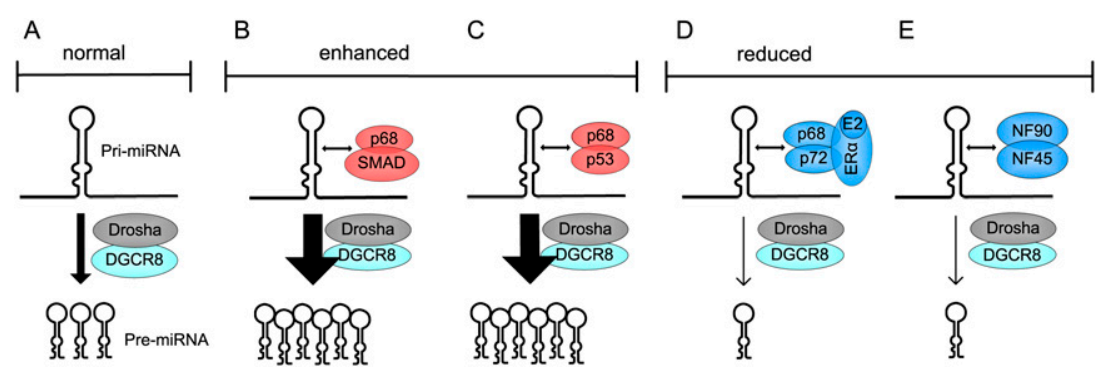

FIGURE 1. MicroRNA processing regulation by Drosha binding or Drosha-associated proteins. (A) Primary miRNA transcript (Pri-miRNA) is processed by Drosha/DGCR8 complex to precursor miRNA (Pre-miRNA). (B) SMAD associates with pri-miR-21, p68, and Drosha/DGCR8 complex to enhance pri-miR-21 processing. (C) Association of p53 with primiR-16-1 and pri-miR-143, p68, and Drosha/DGCR8 enhances pri-miR-16-1 and pri-miR-143 processing. (D) p68/p72 complex mediates inhibition of pri-miR-16, pri-miR-125a, pri-miR143, pri-miR-145, and pri-miR-195 upon stimulation of estrogen receptor $\alpha$ (ER $\alpha$ ) by estradiol (E2). (E) Nuclear factor (NF) 90/45 complex inhibits Drosha/DGCR8 processing by binding to stem/loop fragment of pri-miR-21, pri-miR-15a $\sim 16-1$, and pri-let-7a-1. 
and pri-miR-15a $\sim 16-1$, without affecting the mature miRNA levels (Sakamoto et al. 2009). This suggests that the decreased processing efficiency induced by NF90/NF45 was compensated by other factors. Depletion of NF90 resulted in decreased pri-let-7a-1 levels and increased mature let-7a levels (Sakamoto et al. 2009). The higher binding affinity of NF90/NF45 to pri-let-7a-1, as compared to DGCR8 in vitro, suggested that the reduced miRNA processing efficiency was caused by reducing the accessibility for Drosha-DGCR8 (Sakamoto et al. 2009).

Current literature shows that regulatory proteins are a dominant factor in the regulation of Drosha-mediated pri-miRNA processing. Moreover, various signaling pathways enhance or reduce the efficiency of this step. It is likely that more Drosha-associated proteins regulate miRNA processing, and, as such, the balance between positive and negative regulators may determine the efficiency of miRNA processing.

\section{Dicer binding proteins}

Dicer interacts with Tar RNA binding protein (TRBP) and protein activator of PKR (PACT) and one of the Ago (1-4) proteins, mainly Ago2 (Chendrimada et al. 2005; Haase et al. 2005; Lee et al. 2006). TRBP and PACT facilitate RISC assembly, and they are not essential for miRNA processing (Haase et al. 2005; Lee et al. 2006). However, phosphorylated TRBP stabilized the Dicer-containing complex (Paroo et al. 2009). Expression of phospho-mimic TRBP resulted in increased levels of growth-promoting miRNAs like miR-17, miR-20a, and miR-92 and decreased the level of the growth-inhibitory miRNA let$7 \mathrm{a}$ (Paroo et al. 2009). However, let-7a level is affected indirectly via a mechanism that may involve other proteins like Lin28 (Paroo et al. 2009). TRBP phosphorylation was mediated by the mitogenactivated protein kinase (MAPK) signaling pathway. Therefore, alteration of miRNA processing by ERK may result in a pro-growth phenotype.

Ago proteins are important for proper miRNA function. However, they can also influence miRNA expression. Ectopically expressed Ago proteins (Ago1-4) enhanced expression of some miRNAs including miR-215, miR-17-5p, miR-23b, and miR-92 (Diederichs and Haber 2007). Additionally, Ago2, which has intrinsic endonuclease activity in mammals (Song et al. 2004), induced cleavage of pre-miRNAs leading to an alternative processing intermediate with cleaved $3^{\prime}$-arms of the hairpin (Diederichs and Haber 2007). This intermediate did not change processing to mature miRNA, but may facilitate miRNA duplex dissociation and formation of RISC complex. Dicer-associated proteins, especially TRBP, clearly play a role in the regulation of miRNA processing. However, the mechanisms and specificity of this regulation remain unknown.

\section{Terminal loop binding proteins}

Processing of primary and precursor miRNAs (Fig. 2A) can be regulated by terminal loop binding proteins resulting in either reduced or enhanced processing efficiency. Members of the let-7 family were shown to be post-transcriptionally regulated during differentiation of human embryonic stem cells (Suh et al. 2004), development of mice (Thomson et al. 2006), and neural differentiation of embryocarcinoma cells (Wulczyn et al. 2007). In all cases, Lin28, the developmentally regulated RNA binding protein, was shown to inhibit pri-let-7 processing (Fig. 2B; Newman et al. 2008; Piskounova et al. 2008; Rybak et al. 2008; Viswanathan et al. 2008). Lin28 interacted with the terminal loop region via a conserved sequence, inhibiting processing of pri- and pre-miRNA (Newman et al. 2008; Piskounova et al. 2008; Rybak et al. 2008; Viswanathan et al. 2008). Suppression of let-7 in neural stem cells led to up-regulation of Lin28 and failure of pre-let-7 processing (Rybak et al. 2008). These results suggest a feedback loop between let-7 and Lin28. Lin28 causes terminal uridylation of pre-let-7 in the cytoplasm (Heo et al. 2008) leading to inhibition of Dicer processing and inducing guidance of pre-let-7 to a degradation pathway

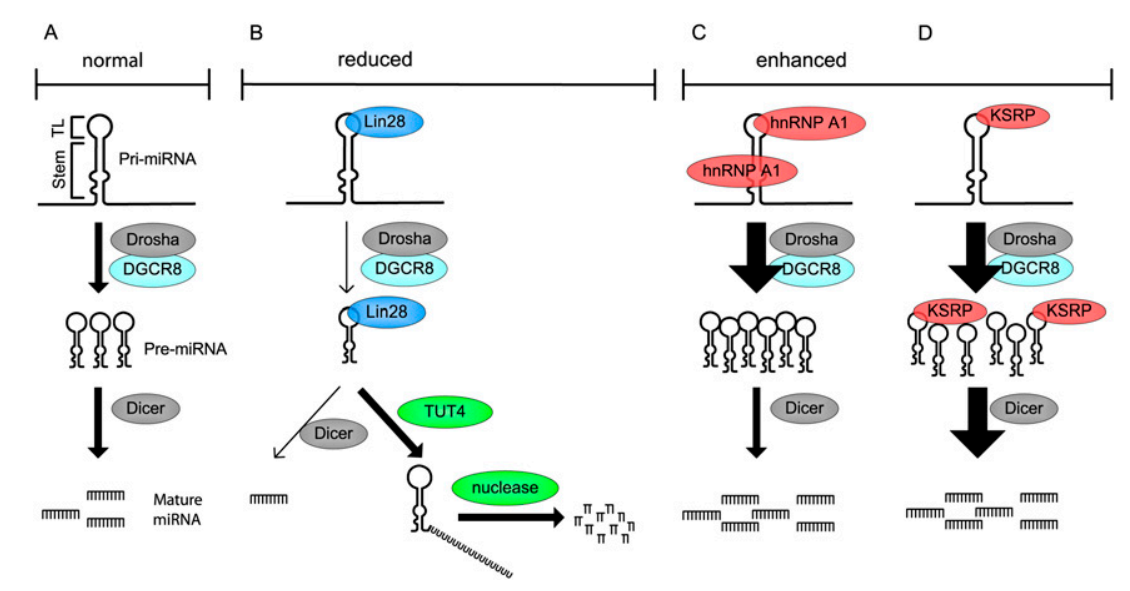

FIGURE 2. MicroRNA processing regulation by terminal loop binding proteins. (A) Primary miRNA transcript (Pri-miRNA) is processed by Drosha/DGCR8 complex to precursor miRNA (Pre-miRNA) and by Dicer to mature miRNA. Stem and terminal loop (TL) regions are assigned within pri-miRNA. (B) Lin28 protein binds to the terminal loop of pri- and premiRNAs from the let-7 family and impairs processing by reducing Drosha and Dicer cleavage and causing uridylation of pre-miR by terminal uridylyl transferase 4 (TUT4) leading to degradation of pre-miR by an unidentified nuclease. $(C)$ Heterogeneous nuclear ribonucleoprotein (hnRNP)-Al binds to the terminal loop and stem of pri-miR-18a and facilitates its processing by Drosha. $(D) \mathrm{KH}$-type splicing regulatory protein (KSRP) binds to the terminal loop of a set of pri- and pre-miRNAs including let-7a, miR-20, miR-26b, miR-106a, miR-21, miR-16, and enhances both Drosha/DGCR8 and Dicer processing. 
(Fig. 2B). A terminal uridylyl transferase 4 (TUTase 4, TUT4) has been shown to be responsible for the pre-let-7 uridylation (Hagan et al. 2009; Heo et al. 2009; Lehrbach et al. 2009). Binding of TUT4 to pre-let-7 is dependent on the presence of Lin28, confirming that Lin28 is necessary for recruiting TUT4.

The RNA binding protein heterogeneous nuclear ribonucleoprotein A1 (hnRNP A1) has been reported to facilitate processing of miR-18a, a member of the miR17 92 cluster (Fig. 2C; Guil and Cáceres 2007). Knockdown of $h n R N P A 1$ resulted in inhibition of pri- to pre-miR-18a processing, but did not affect other members of this cluster. This might in part explain variations in levels of the individual mature miRNA members of this cluster ( $\mathrm{Yu}$ et al. 2006; Lu et al. 2007; Mendell 2008). hnRNP A1 binds to both the terminal loop and a region in the stem of pri-miR-18a (Michlewski et al. 2008), causing relaxation of the stem and facilitating Drosha/DGCR8 processing. The possible effect of hnRNP A1 binding on the Dicer processing step has not been investigated for miR-18a. hnRNP A1 also binds to the terminal loops of pri-let-7a-1 and primiR-101-1, indicating that this protein might also regulate processing of other pri-miRNAs. This is consistent with the more general RNA binding properties of hnRNP A1 (Mayeda and Krainer 1992; Martinez-Contreras et al. 2006).

Another RNA binding protein proven to be involved in miRNA processing is the KH-type splicing regulatory protein (KSRP). KSRP is known as a key mediator of AU-rich element (ARE)-directed mRNA decay that facilitates recruitment of the degradation machinery to AREcontaining mRNAs (Gherzi et al. 2004; García-Mayoral et al. 2007). KSRP was shown to be a component of both Drosha and Dicer complexes and promoted biogenesis of a cohort of miRNAs including let-7a, miR-21, and miR-16 (Fig. 2D; Trabucchi et al. 2009). KSRP binds to the terminal loop of its target primary and/or precursor miRNAs and induces processing by Drosha and Dicer complexes through protein-protein interactions (Trabucchi et al. 2009). Moreover, KSRP mediates induction of miR-155 processing in macrophages upon LPS stimulation that is also achieved by binding to the terminal loop (Ruggiero et al. 2009).

Conservation of terminal loop sequences across vertebrate species can be found in $\sim 14 \%$ ( 74 out of 533 ) of the miRNAs indicating that the loops of these miRNAs are functionally important (Michlewski et al. 2008). To analyze the relevance of these conserved terminal loop sequences, Michlewski et al. (2008) showed that oligonucleotides complementary to the sequence of conserved terminal loops abolished the in vitro processing of pri-miR-18a, pri-miR-31, pri-miR-101-1, pri-miR-379, and pri-let-7a-1. Pri-miRNAs without conserved loops (pri-miR-16-1, primiR-27a) were not affected by antisense loop oligo's (Michlewski et al. 2008).

These studies clearly demonstrate that terminal loop binding proteins play an important role in the regulation of miRNA processing. Therefore, it is highly likely that other RNA binding proteins may also be involved in the regulation of processing of individual miRNAs.

\section{Cellular location}

Exportin-5 mediates the nuclear export of pre-miRNAs to the cytoplasm and protects pre-miRNAs from digestion (Bohnsack et al. 2004; Lund et al. 2004). The length of the double-stranded stem and presence of $3^{\prime}$ overhangs but not the sequence or the loop structure are important for proper recognition of pre-miRNAs by Exportin-5 (Lund et al. 2004; Zeng and Cullen 2004).

A blockade in the transport of pre-miRNAs from nucleus to cytoplasm was suggested to explain the high levels of precursor and lack of mature miR-128a, miR-105, and miR31 in some cancer cell lines. This was supported by the predominant nuclear localization of primary/precursors detected by in situ RT-PCR (Lee et al. 2008). A debatable example for premature nuclear export is BIC (pri-miR-155) (van den Berg et al. 2003; Eis et al. 2005; Kluiver et al. 2005). RNA in situ hybridization (ISH) using a probe complementary to the $3^{\prime}$ part of exon 3 revealed a strong nuclear staining in various lymphoma subtypes and in normal B-cells. This exon contains the stem-loop region of miR-155, indicating an appropriate location. Eis at al. (2005) showed a cytoplasmic location of spliced $B I C$ transcripts and a nuclear location of the unspliced $B I C$ transcript in two lymphoma cell lines by RT-PCR of RNA isolated from purified nuclear and cytoplasmic fractions. These data might indicate that the unspliced BIC transcript serves as a source for miR-155. However, this does not explain the specific nuclear localization for BIC using RNA-ISH. Since both cell lines tested by Eis at al. (2005) showed a high level of miR-155, it remains unclear if premature export of spliced BIC transcripts explains the low miR-155 levels observed in Burkitt lymphoma cell lines after induction of BIC (Kluiver et al. 2007). Based on current literature, the importance of nuclear export in miRNA processing regulation remains uncertain.

\section{Sequence alterations in DNA/RNA}

Alteration of miRNA processing can be caused not only by changes in the processing machinery, but also due to sequence alterations in the miRNA genes or RNA transcripts. In $15 \%$ of patients with chronic lymphocytic leukemia (CLL), but not in healthy controls, mutations were found in five of 42 analyzed miRNA genes (Calin et al. 2005). Moreover, a germline mutation located in the miR$15 \mathrm{a} \sim 16$ - 1 genomic DNA, 7 bp downstream from pre-miR16-1, resulted in lower levels of the mature miRNAs (Calin et al. 2005). However, it remains to be established whether this effect is caused by aberrant transcription or processing.

Besides mutations, alterations at the miRNA transcript level caused by RNA editing can affect miRNA processing (Fig. 3). RNA editing is conducted by adenosine deaminases 


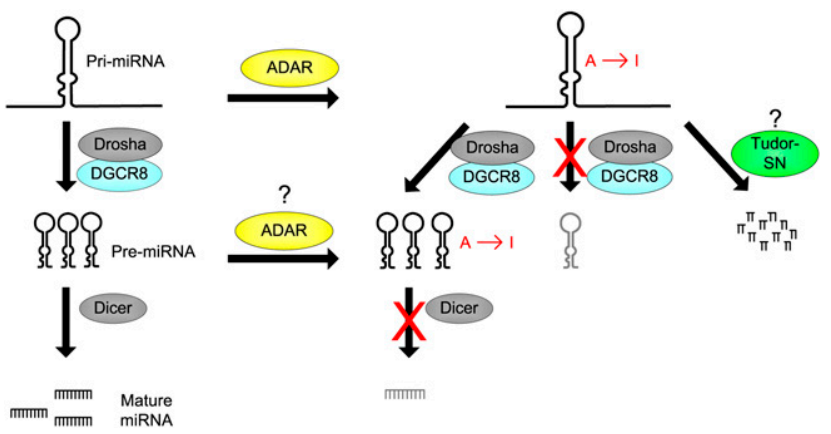

FIGURE 3. Regulation of miRNA processing by ADAR editing. Adenosine deaminases acting on RNA (ADARs) can convert adenosine to inosine in pri-miRNA; conversion of pre-miRNA is also possible, but has not been proven. ADAR editing can lead to blockade in Drosha cleavage of pri-miR-142 and degradation of edited primiR-142 by a ribonuclease Tudor-SN. ADAR editing can also block Dicer processing of pri-miR-151 causing accumulation of edited premiR-151.

acting on RNA (ADARs) that convert adenosine (A) to inosine (I) in dsRNA structures (Bass 2002; Maas et al. 2003; Amariglio and Rechavi 2007). The primary transcript of miR-22 was the first miRNA shown to undergo A-to-I editing at positions that surround the Drosha cleavage site (Luciano et al. 2004). However, the physiological role of miR-22 editing has not been revealed yet. Another primary miRNA found to be edited by ADAR1 and ADAR2 isoforms in vitro is pri-miR-142 (Yang et al. 2006b). A-to-I editing of pri-miR-142 resulted in reduced Drosha processing in HEK293 cells. However, no accumulation of edited pri-miR-142 was observed in the nucleus. Edited pri-miR142 was shown to be cleaved in vitro by Tudor-SN (Yang et al. 2006b), a component of RISC, with ribonuclease activity specific to inosine-containing dsRNAs (Scadden 2005). However, the relevance of Tudor-SN for in vivo degradation of edited pri-miRNAs is still uncertain. ADAR editing of the pri-miRNA can also inhibit Dicer cleavage (Kawahara et al. 2007a). Editing of pri-miR-151 by ADAR1 did not affect pri-miRNA to pre-miRNA processing but caused inhibition of pre- to mature miR-151 processing as proven by accumulation of edited pre-miR-151. The inhibition at the Dicer cleavage step was investigated using synthetic pre-miR-151 in vitro. Although there was efficient binding of the Dicer-TRBP complex to pre-miR-151, the cleavage of pre- and release of mature form was blocked. Analysis of editing sites revealed that only a small proportion of the pri-miR-151 transcripts were edited at a specific site. Moreover, high frequency of pre-miR-151 editing has been shown in vitro. Therefore, A-to-I editing may occur also after processing of pri- to pre-miR-151 (Kawahara et al. 2007a). Moreover, ADAR editing may interfere with miRNA function by changing the "seed" region, which is crucial for target gene binding. The edited isoform of miR-376 inhibited a different set of genes than the normal form, supporting this concept (Kawahara et al. 2007b).
Since ADARs are predominantly nuclear enzymes, their targets are most likely pri-miRNAs and pre-miRNAs before nuclear export. However, some ADAR isoforms shuttle in and out of the nucleus (Desterro et al. 2003) and may edit pre-miRNA in the cytoplasm (Kawahara et al. 2007a). Although it is obvious that ADAR editing is a regulated event, there is not much known about the relevance of ADAR editing and the fate of edited miRNAs.

\section{Single nucleotide polymorphisms}

Polymorphisms in a miRNA gene may alter miRNA processing by changing the stem-loop structure. Although this is not an active processing regulation mechanism, it is evident that SNPs do alter the processing efficiency (Fig. 4).

The first study that identified SNPs in miRNA precursors was performed by Iwai and Naraba (2005). However, no effect was observed for the processing efficiency of the two alleles of pre-miR-30c-2. The other nine SNPs that were identified in this study have not been tested (Iwai and Naraba 2005). Duan et al. (2007) systematically identified 323 SNPs that were associated with 227 human miRNA genes. Twelve of these SNPs were found in miRNA precursor sequences, and one SNP was located in the miR125a seed sequence. Transfection of HEK293T cells with vectors expressing one of the two miR-125a precursor variants revealed that only one of the variants could be processed into mature miRNA. The blockade of the other

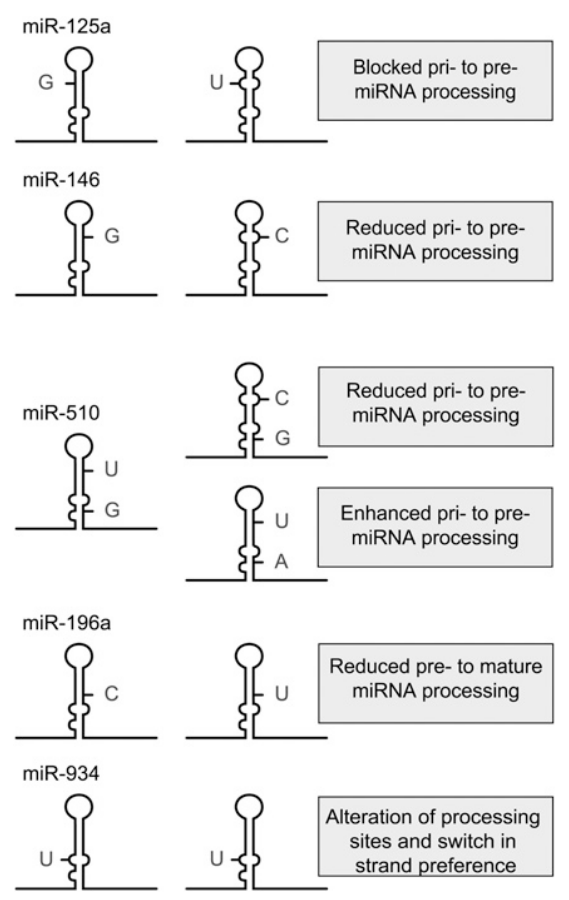

FIGURE 4. Influence of SNPs on miRNA processing. SNP variants of miR-125a, miR-146, miR-510, miR-196a, and miR-934 are processed differently due to changes in a stem structure or processing sites. Major alleles are situated on the left side; minor alleles on the right. 
allele occurred at the pri- to pre-miR-125a processing step (Duan et al. 2007). Difference in Drosha/DGCR8 processing was also proven for the two alleles of miR-146a (rs2910164), miR-502, miR-510, miR-890, and miR-892b (Jazdzewski et al. 2008; Sun et al. 2009). Possibly, the SNP affects the binding efficiency of the Drosha/DGCR8 complex. The T/G SNP in miR-934 altered processing efficiency, strand preference, and the mature miRNA sequence (Sun et al. 2009). In human lung cancer tissue, similar premiR-196a levels were observed for both alleles of the C/T SNP (rs11614913), whereas a marked difference was observed for the mature miR-196a levels, indicating an alteration in the pre- to mature miRNA processing step (Hu et al. 2008). This suggests interference with the nuclear export or the Dicer processing step of pre-miR-196a by the SNP. Together, these studies demonstrate that SNPs in miRNA genes can significantly affect miRNA processing and in some cases also miRNA function.

\section{CONCLUDING REMARKS}

Recent studies have shown that miRNA biogenesis involves a number of tightly regulated processing steps that provide an important regulatory mechanism to define cellular levels of specific miRNAs. Therefore, biogenesis of miRNAs should not be regarded as a linear, unified mechanism. Based on current studies, Drosha, Dicer, and terminal loop binding proteins are the main factors involved in miRNA processing regulation. Cellular localization and ADAR editing influence processing of certain miRNAs, but their overall impact seems to be limited.

It is evident that proteins known to regulate transcription (p53, SMADs) or mRNA stability (KSRP) can also influence miRNA processing efficiency and therefore have the ability to control cellular levels of miRNAs. In some cases, complex networks have been reported to regulate processing of specific miRNAs; i.e., processing of miR-16, miR-143, and miR-145 is facilitated by $\mathrm{p} 53$ and inhibited by ER $\alpha$ in a p68/p72-dependent mechanism, and let-7 processing is negatively regulated by $\operatorname{Lin} 28$ and positively by KSRP. The terminal loop was shown to be an important target structure for regulation of miRNA expression by binding to activators and/or inhibitors of the miRNA processing machinery. This form of regulation may facilitate a much faster response to cellular changes as compared to the transcriptional control of miRNA genes. Moreover, the change in expression of one miRNA leads to differential expression of many miRNA target genes and may provide not only a quick but also a broad response to various stimuli.

Although knowledge about regulatory proteins is expanding rapidly, future studies should focus on identifying additional regulatory proteins. Human homologs of proteins regulating miRNA processing in plants, i.e., SERRATE and cap binding proteins CBP80/CBP20 (Lobbes et al. 2006; Yang et al. 2006a; Kim et al. 2008; Laubinger et al. 2008) need to be studied to define possible parallel regulatory functions in the processing of miRNA.

It is evident that several mechanisms regulate efficiency of miRNA processing. Nevertheless, for some miRNAs, inconsistencies between primary, precursor, and mature miRNA have been observed in certain normal or cancer cells. The mechanisms for these inconsistencies (Table 1) are still unknown. For instance, no specific mechanism has been related to the tissue-specific expression levels of mature, but not precursor, miR-138 or miR-128 (Table 1; Obernosterer et al. 2006; Lee et al. 2008). An overall decrease of miRNA expression has been observed in many types of cancer as compared to their normal counterparts, and the underlying mechanisms remain unknown ( $\mathrm{Lu}$ et al. 2005; Chen and Stallings 2007; Ozen et al. 2008). Inconsistencies between pri- and mature miRNAs are most obvious for the so-called polycistronic or miRNA clusters and indicate a miRNA-specific regulation. Based on current knowledge, it seems likely that the currently known mechanisms that regulate miRNA processing are, at least partially, involved in the deregulated miRNA expression levels in cancer. However, detailed comparisons between the regulations of miRNA processing in cancer cells as compared to their normal counterparts have not been performed. Elucidation of putative differences between normal and cancer cells and manipulation of these regulatory

TABLE 1. miRNAs that may undergo processing regulation by a currently unknown mechanism

\begin{tabular}{|c|c|c|c|}
\hline Altered miRNA ${ }^{a}$ & Compared tissues or cells & Inconsistency between & Reference \\
\hline miR-7 $\downarrow$ & Glioblastoma/normal brain & Primary/precursor and mature & Kefas et al. 2008 \\
\hline $\operatorname{miR}-128 \uparrow$ & Brain, skeletal muscle/other tissues & Primary, precursor/mature & Lee et al. 2008 \\
\hline $\operatorname{miR}-138 \uparrow$ & Brain, neuroblastoma/other tissues & Precursor/mature & Obernosterer et al. 2006 \\
\hline miR-143 $\downarrow$ miR-145 $\downarrow$ & Colorectal adenocarcinoma/normal mucosa & Precursor/mature & Michael et al. 2003 \\
\hline miR-155 $\downarrow$ & $\begin{array}{l}\text { Burkitt lymphoma with elevated } \\
\text { pri-miR-155/other cells }\end{array}$ & Primary/mature & Kluiver et al. 2007 \\
\hline miR-206 $\downarrow$ & $\begin{array}{l}\text { Mouse myoblast cells with elevated } \\
\text { pri-miR-206/other cells }\end{array}$ & Primary/mature & Sato et al. 2009 \\
\hline
\end{tabular}


processes might provide a novel approach to restore a normal miRNA profile in cancer cells.

Undoubtedly, many factors regulating the cellular miRNA levels are still unknown. Further unraveling of the mechanisms responsible for regulation of the miRNA processing machinery will be an important step in elucidating the pathophysiological significance of miRNAs in malignancies and open up venues for treatment.

\section{ACKNOWLEDGMENT}

We thank Dr. Johan H. Gibcus for help with preparing the figures.

\section{REFERENCES}

Amariglio N, Rechavi G. 2007. A-to-I RNA editing: A new regulatory mechanism of global gene expression. Blood Cells Mol 39: 151-155.

Bartel DP. 2004. MicroRNAs: Genomics, biogenesis, mechanism, and function. Cell 116: 281-297.

Bass BL. 2002. RNA editing by adenosine deaminases that act on RNA. Annu Rev Biochem 71: 817-846.

Bohnsack MT, Czaplinski K, Gorlich D. 2004. Exportin 5 is a RanGTPdependent dsRNA-binding protein that mediates nuclear export of pre-miRNAs. RNA 10: 185-191.

Calin GA, Ferracin M, Cimmino A, Di Leva G, Shimizu M, Wojcik SE, Iorio MV, Visone R, Sever NI, Fabbri M, et al. 2005. A microRNA signature associated with prognosis and progression in chronic lymphocytic leukemia. $N$ Engl J Med 353: 1793-1801.

Chen Y, Stallings RL. 2007. Differential patterns of microRNA expression in neuroblastoma are correlated with prognosis, differentiation, and apoptosis. Cancer Res 67: 976-983.

Chendrimada TP, Gregory RI, Kumaraswamy E, Norman J, Cooch N, Nishikura K, Shiekhattar R. 2005. TRBP recruits the Dicer complex to Ago2 for microRNA processing and gene silencing. Nature 436: 740-744.

Davis BN, Hilyard AC, Lagna G, Hata A. 2008. SMAD proteins control DROSHA-mediated microRNA maturation. Nature 454: $56-61$.

Denli AM, Tops BB, Plasterk RH, Ketting RF, Hannon GJ. 2004. Processing of primary microRNAs by Microprocessor complex. Nature 432: 231-235.

Desterro JM, Keegan LP, Lafarga M, Berciano MT, O'Connell M, Carmo-Fonseca M. 2003. Dynamic association of RNA-editing enzymes with the nucleolus. J Cell Sci 116: 1805-1818.

Diederichs S, Haber DA. 2007. Dual role for argonautes in microRNA processing and posttranscriptional regulation of microRNA expression. Cell 131: 1097-1108.

Duan R, Pak C, Jin P. 2007. Single nucleotide polymorphism associated with mature miR-125a alters the processing of primiRNA. Hum Mol Genet 16: 1124-1131.

Eis PS, Tam W, Sun L, Chadburn A, Li Z, Gomez MF, Lund E, Dahlberg JE. 2005. Accumulation of miR-155 and BIC RNA in human B cell lymphomas. Proc Natl Acad Sci 102: 3627-3632.

Eulalio A, Huntzinger E, Izaurralde E. 2008. Getting to the root of miRNA-mediated gene silencing. Cell 132: 9-14.

Filipowicz W, Bhattacharyya SN, Sonenberg N. 2008. Mechanisms of post-transcriptional regulation by microRNAs: Are the answers in sight? Nat Rev Genet 9: 102-114.

Fukuda T, Yamagata K, Fujiyama S, Matsumoto T, Koshida I, Yoshimura K, Mihara M, Naitou M, Endoh H, Nakamura T, et al. 2007. DEAD-box RNA helicase subunits of the Drosha complex are required for processing of rRNA and a subset of microRNAs. Nat Cell Biol 9: 604-611.

García-Mayoral MF, Hollingworth D, Masino L, Díaz-Moreno I, Kelly G, Gherzi R, Chou CF, Chen CY, Ramos A. 2007. The structure of the C-terminal $\mathrm{KH}$ domains of KSRP reveals a noncanonical motif important for mRNA degradation. Structure 15: 485-498.

Gherzi R, Lee KY, Briata P, Wegmüller D, Moroni C, Karin M, Chen CY. 2004. A KH domain RNA binding protein, KSRP, promotes ARE-directed mRNA turnover by recruiting the degradation machinery. Mol Cell 14: 571-583.

Gregory RI, Yan KP, Amuthan G, Chendrimada T, Doratotaj B, Cooch N, Shiekhattar R. 2004. The Microprocessor complex mediates the genesis of MicroRNAs. Nature 432: 235-240.

Grishok A, Pasquinelli AE, Conte D, Li N, Parrish S, Ha I, Baillie DL, Fire A, Ruvkun G, Mello CC. 2001. Genes and mechanisms related to RNA interference regulate expression of the small temporal RNAs that control C. elegans developmental timing. Cell 106: $23-$ 34.

Guil S, Cáceres JF. 2007. The multifunctional RNA-binding protein hnRNP-Al is required for processing of miR-18a. Nat Struct Mol Biol 14: 591-596.

Haase AD, Jaskiewicz L, Zhang H, Lainé S, Sack R, Gatignol A, Filipowicz W. 2005. TRBP, a regulator of cellular PKR and HIV-1 virus expression, interacts with Dicer and functions in RNA silencing. EMBO Rep 6: 961-967.

Hagan JP, Piskounova E, Gregory RI. 2009. Lin28 recruits the TUTase Zcchc11 to inhibit let-7 maturation in mouse embryonic stem cells. Nat Struct Mol Biol 16: 1021-1025.

Han J, Lee Y, Yeom KH, Kim YK, Jin H, Kim VN. 2004. The DroshaDGCR8 complex in primary microRNA processing. Genes Dev 18: 3016-3027.

He L, He X, Lim LP, de Stanchina E, Xuan Z, Liang Y, Xue W, Zender L, Magnus J, Ridzon D, et al. 2007. A microRNA component of the p53 tumor suppressor network. Nature 447: 1130-1134.

Heo I, Joo C, Cho J, Ha M, Han J, Kim VN. 2008. Lin28 mediates the terminal uridylation of let-7 precursor microRNA. Mol Cell 32: 276-284.

Heo I, Joo C, Kim YK, Ha M, Yoon MJ, Cho J, Yeom KH, Han J, Kim VN. 2009. TUT4 in concert with Lin28 suppresses microRNA biogenesis through pre-microRNA uridylation. Cell 138: 696-708.

Hu Z, Chen J, Tian T, Zhou X, Gu H, Xu L, Zeng Y, Miao R, Jin G, $\mathrm{Ma} \mathrm{H}$, et al. 2008. Genetic variants of miRNA sequences and nonsmall cell lung cancer survival. J Clin Invest 118: 2600-2608.

Hutvagner G, McLachlan J, Pasquinelli AE, Balint E, Tuschl T, Zamore PD. 2001. A cellular function for the RNA interference enzyme Dicer in the maturation of the let-7 small temporal RNA. Science 293: 834-838.

Iwai N, Naraba H. 2005. Polymorphisms in human pre-miRNAs. Biochem Biophys Res Commun 331: 1439-1444.

Jazdzewski K, Murray EL, Franssila K, Jarzab B, Schoenberg DR, de la Chapelle A. 2008. Common SNP in pre-miR-146a decreases mature miR expression and predisposes to papillary thyroid carcinoma. Proc Natl Acad Sci 105: 7269-7274.

Kawahara Y, Zinshteyn B, Chendrimada TP, Shiekhattar R, Nishikura K. 2007a. RNA editing of the microRNA-151 precursor blocks cleavage by the Dicer-TRBP complex. EMBO Rep 8: 763769.

Kawahara Y, Zinshteyn B, Sethupathy P, Iizasa H, Hatzigeorgiou AG, Nishikura K. 2007b. Redirection of silencing targets by adenosineto-inosine editing of miRNAs. Science 315: 1137-1140.

Kefas B, Godlewski J, Comeau L, Li Y, Abounader R, Hawkinson M, Lee J, Fine H, Chiocca AE, Lawler S, et al. 2008. microRNA-7 inhibits the epidermal growth factor receptor and the Akt pathway and is down-regulated in glioblastoma. Cancer Res 68: 3566-3572.

Kim VN, Nam JW. 2006. Genomics of microRNA. Trends Genet 22: 165-173.

Kim S, Yang JY, Xu J, Jang IC, Prigge MJ, Chua NH. 2008. Two cap binding proteins CBP20 and CBP80 are involved in processing primary microRNAs. Plant Cell Physiol 49: 1634-1644.

Kluiver J, Poppema S, de Jong D, Blokzijl T, Harms G, Jacobs S, Kroesen BJ, van den Berg A. 2005. BIC and miR-155 are highly 
expressed in Hodgkin, primary mediastinal and diffuse large B cell lymphomas. J Pathol 207: 243-249.

Kluiver J, van den Berg A, de Jong D, Blokzijl T, Harms G, Bouwman E, Jacobs S, Poppema S, Kroesen BJ. 2007. Regulation of pri-microRNA BIC transcription and processing in Burkitt lymphoma. Oncogene 26: 3769-3776.

Landthaler M, Yalcin A, Tuschl T. 2004. The human DiGeorge syndrome critical region gene 8 and its D. melanogaster homo$\log$ are required for miRNA biogenesis. Curr Biol 14: 2162 2167.

Laubinger S, Sachsenberg T, Zeller G, Busch W, Lohmann JU, Rätsch G, Weigel D. 2008. Dual roles of the nuclear cap-binding complex and SERRATE in pre-mRNA splicing and microRNA processing in Arabidopsis thaliana. Proc Natl Acad Sci 105: 87958800.

Lee RC, Feinbaum RL, Ambros V. 1993. The C. elegans heterochronic gene lin-4 encodes small RNAs with antisense complementarity to lin-14. Cell 75: 843-854.

Lee Y, Ahn C, Han J, Choi H, Kim J, Yim J, Lee J, Provost P, Radmark O, Kim S, et al. 2003. The nuclear RNase III Drosha initiates microRNA processing. Nature 425: 415-419.

Lee Y, Hur I, Park SY, Kim YK, Suh MR, Kim VN. 2006. The role of PACT in the RNA silencing pathway. EMBO J 25: 522-532.

Lee EJ, Baek M, Gusev Y, Brackett DJ, Nuovo GJ, Schmittgen TD. 2008. Systematic evaluation of microRNA processing patterns in tissues, cell lines, and tumors. RNA 14: 35-42.

Lehmann U, Hasemeier B, Christgen M, Müller M, Römermann D, Länger F, Kreipe H. 2007. Epigenetic inactivation of microRNA gene hsa-miR-9-1 in human breast cancer. J Pathol 214: 17-24.

Lehrbach NJ, Armisen J, Lightfoot HL, Murfitt KJ, Bugaut A, Balasubramanian S, Miska EA. 2009. LIN-28 and the poly(U) polymerase PUP-2 regulate let-7 microRNA processing in Caenorhabditis elegans. Nat Struct Mol Biol 16: 1016-1020.

Lobbes D, Rallapalli G, Schmidt DD, Martin C, Clarke J. 2006. SERRATE: A new player on the plant microRNA scene. EMBO Rep 7: 1052-1058.

Lu J, Getz G, Miska EA, Alvarez-Saavedra E, Lamb J, Peck D, SweetCordero A, Ebert BL, Mak RH, Ferrando AA, et al. 2005. MicroRNA expression profiles classify human cancers. Nature 435: 834838 .

Lu Y, Thomson JM, Wong HY, Hammond SM, Hogan BL. 2007. Transgenic over-expression of the microRNA miR-17-92 cluster promotes proliferation and inhibits differentiation of lung epithelial progenitor cells. Dev Biol 310: 442-453.

Luciano DJ, Mirsky H, Vendetti NJ, Maas S. 2004. RNA editing of a miRNA precursor. RNA 10: 1174-1177.

Lujambio A, Ropero S, Ballestar E, Fraga MF, Cerrato C, Setién F, Casado S, Suarez-Gauthier A, Sanchez-Cespedes M, Git A, et al. 2007. Genetic unmasking of an epigenetically silenced microRNA in human cancer cells. Cancer Res 67: 1424-1429.

Lund E, Guttinger S, Calado A, Dahlberg JE, Kutay U. 2004. Nuclear export of microRNA precursors. Science 303: 95-98.

Maas S, Rich A, Nishikura K. 2003. A-to-I RNA editing: Recent news and residual mysteries. J Biol Chem 278: 1391-1394.

Martinez-Contreras R, Fisette JF, Nasim FU, Madden R, Cordeau M, Chabot B. 2006. Intronic binding sites for hnRNP A/B and hnRNP F/H proteins stimulate pre-mRNA splicing. PLoS Biol 4: 172185.

Mayeda A, Krainer AR. 1992. Regulation of alternative pre-mRNA splicing by hnRNPA1 and splicing factor SF2. Cell 68: 365375.

Mendell JT. 2008. miRiad roles for the miR-17-92 cluster in development and disease. Cell 133: 217-222.

Michael MZ, O'Connor SM, van Holst Pellekaan NG, Young GP, James RJ. 2003. Reduced accumulation of specific microRNAs in colorectal neoplasia. Mol Cancer Res 1: 882-891.

Michlewski G, Guil S, Semple CA, Cáceres JF. 2008. Post-transcriptional regulation of miRNAs harboring conserved terminal loops. Mol Cell 32: 383-393.
Newman MA, Thomson JM, Hammond SM. 2008. Lin-28 interaction with the Let-7 precursor loop mediates regulated microRNA processing. RNA 14: 1539-1549.

Obernosterer G, Leuschner PJ, Alenius M, Martinez J. 2006. Posttranscriptional regulation of microRNA expression. RNA 12: $1161-1167$

Okamura K, Hagen JW, Duan H, Tyler DM, Lai EC. 2007. The mirtron pathway generates microRNA-class regulatory RNAs in Drosophila. Cell 130: 89-100.

Ozen M, Creighton CJ, Ozdemir M, Ittmann M. 2008. Widespread deregulation of microRNA expression in human prostate cancer. Oncogene 27: 1788-1793.

Paroo Z, Ye X, Chen S, Liu Q. 2009. Phosphorylation of the human microRNA-generating complex mediates MAPK/Erk signaling. Cell 139: 112-122.

Piskounova E, Viswanathan SR, Janas M, Lapierre RJ, Daley GQ, Sliz P, Gregory RI. 2008. Determinants of microRNA processing inhibition by the developmentally regulated RNA-binding protein Lin28. J Biol Chem 283: 21310-21314.

Ruby JG, Jan CH, Bartel DP. 2007. Intronic microRNA precursors that bypass Drosha processing. Nature 448: 83-86.

Ruggiero T, Trabucchi M, De Santa F, Zupo S, Harfe BD, McManus MT, Rosenfeld MG, Briata P, Gherzi R. 2009. LPS induces KH-type splicing regulatory protein-dependent processing of microRNA-155 precursors in macrophages. FASEB J 23: 2898-2908.

Rybak A, Fuchs H, Smirnova L, Brandt C, Pohl EE, Nitsch R, Wulczyn FG. 2008. A feedback loop comprising lin-28 and let-7 controls pre-let-7 maturation during neural stem-cell commitment. Nat Cell Biol 10: 987-993.

Sakamoto S, Aoki K, Higuchi T, Todaka H, Morisawa K, Tamaki N, Hatano E, Fukushima A, Taniguchi T, Agata Y. 2009. The NF90NF45 complex functions as a negative regulator in the microRNA processing pathway. Mol Cell Biol 29: 3754-3769.

Sato MM, Nashimoto M, Katagiri T, Yawaka Y, Tamura M. 2009. Bone morphogenetic protein-2 down-regulates miR-206 expression by blocking its maturation process. Biochem Biophys Res Commun 383: 125-129.

Scadden AD. 2005. The RISC subunit Tudor-SN binds to hyperedited double-stranded RNA and promotes its cleavage. Nat Struct Mol Biol 12: 489-496.

Scott GK, Mattie MD, Berger CE, Benz SC, Benz CC. 2006. Rapid alteration of microRNA levels by histone deacetylase inhibition. Cancer Res 66: 1277-1281.

Song JJ, Smith SK, Hannon GJ, Joshua-Tor L. 2004. Crystal structure of Argonaute and its implications for RISC slicer activity. Science 305: 1434-1437.

Suh MR, Lee Y, Kim JY, Kim SK, Moon SH, Lee JY, Cha KY, Chung HM, Yoon HS, Moon SY, et al. 2004. Human embryonic stem cells express a unique set of microRNAs. Dev Biol 270: 488-498.

Sun G, Yan J, Noltner K, Feng J, Li H, Sarkis DA, Sommer SS, Rossi JJ. 2009. SNPs in human miRNA genes affect biogenesis and function. RNA 15: 1640-1651.

Suzuki HI, Yamagata K, Sugimoto K, Iwamoto T, Kato S, Miyazono K. 2009. Modulation of microRNA processing by p53. Nature 460: 529-533.

Thomson JM, Newman M, Parker JS, Morin-Kensicki EM, Wright T, Hammond SM. 2006. Extensive post-transcriptional regulation of microRNAs and its implications for cancer. Genes Dev 20: 22022207.

Trabucchi M, Briata P, Garcia-Mayoral M, Haase AD, Filipowicz W, Ramos A, Gherzi R, Rosenfeld MG. 2009. The RNA-binding protein KSRP promotes the biogenesis of a subset of microRNAs. Nature 459: 1010-1014.

van den Berg A, Kroesen BJ, Kooistra K, de Yong D, Briggs J, Blokzijl T, Jacobs S, Kluiver J, Diepstra A, Maggio E, et al. 2003. High expression of B-cell receptor inducible gene BIC in all subtypes of Hodgkin's lymphoma. Genes Chromosomes Cancer 37: 20-28.

Viswanathan SR, Daley GQ, Gregory RI. 2008. Selective blockade of microRNA processing by Lin28. Science 320: 97-100. 
Wightman B, Ha I, Ruvkun G. 1993. Post-transcriptional regulation of the heterochronic gene lin-14 by lin-4 mediates temporal pattern formation in C. elegans. Cell 75: 855-862.

Woods K, Thomson JM, Hammond SM. 2007. Direct regulation of an oncogenic micro-RNA cluster by E2F transcription factors. J Biol Chem 282: 2130-2134.

Wulczyn FG, Smirnova L, Rybak A, Brandt C, Kwidzinski E, Ninnemann O, Strehle M, Seiler A, Schumacher S, Nitsch R. 2007. Post-transcriptional regulation of the let-7 microRNA during neural cell specification. FASEB J 21: 415-426.

Xi Y, Shalgi R, Fodstad O, Pilpel Y, Ju J. 2006. Differentially regulated microRNAs and actively translated messenger RNA transcripts by tumor suppressor p53 in colon cancer. Clin Cancer Res 12: 2014-2024.

Yamagata K, Fujiyama S, Ito S, Ueda T, Murata T, Naitou M, Takeyama K, Minami Y, O’Malley BW, Kato S. 2009. Maturation of microRNA is hormonally regulated by a nuclear receptor. $\mathrm{Mol}$ Cell 36: 340-347.
Yang L, Liu Z, Lu F, Dong A, Huang H. 2006a. SERRATE is a novel nuclear regulator in primary microRNA processing in Arabidopsis. Plant J 47: 841-850.

Yang W, Chendrimada TP, Wang Q, Higuchi M, Seeburg PH, Shiekhattar R, Nishikura K. 2006b. Modulation of microRNA processing and expression through RNA editing by ADAR deaminases. Nat Struct Mol Biol 13: 13-21.

Yi R, Qin Y, Macara IG, Cullen BR. 2003. Exportin-5 mediates the nuclear export of pre-microRNAs and short hairpin RNAs. Genes Dev 17: 3011-3016.

Yu J, Wang F, Yang GH, Wang FL, Ma YN, Du ZW, Zhang JW. 2006. Human microRNA clusters: Genomic organization and expression profile in leukemia cell lines. Biochem Biophys Res Commun 349: 59-68.

Zeng Y, Cullen BR. 2004. Structural requirements for pre-microRNA binding and nuclear export by Exportin 5. Nucleic Acids Res 32: 4776-4785. 

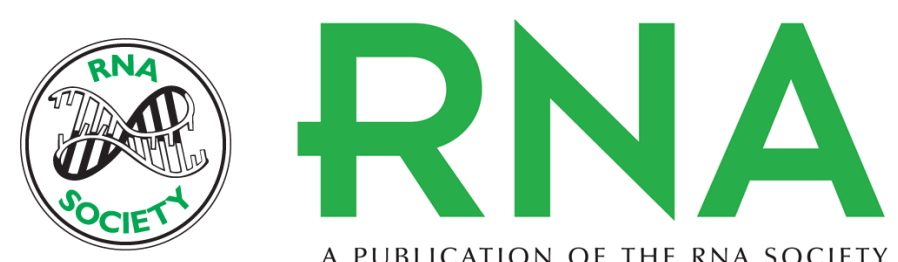

A PUBLICATION OF THE RNA SOCIETY

\section{MicroRNAs, macrocontrol: Regulation of miRNA processing}

Izabella Slezak-Prochazka, Selvi Durmus, Bart-Jan Kroesen, et al.

RNA 2010 16: 1087-1095 originally published online April 27, 2010

Access the most recent version at doi:10.1261/rna.1804410

\section{References}

This article cites 89 articles, 30 of which can be accessed free at: http://rnajournal.cshlp.org/content/16/6/1087.full.html\#ref-list-1

License

Email Alerting Service

Receive free email alerts when new articles cite this article - sign up in the box at the top right corner of the article or click here. 